\title{
4-Hydroxyisoleucine improves insulin resistance in HepG2 cells by decreasing TNF- $\alpha$ and regulating the expression of insulin signal transduction proteins
}

\author{
FENG GAO $^{1}$, LIUMENG JIAN ${ }^{1}$, MOHAMMAD ISHRAQ ZAFAR $^{1}$, WEN DU ${ }^{1}$, \\ QIN CAI $^{1}$, RAJA ADEEL SHAFQAT ${ }^{2}$ and FURONG LU ${ }^{3}$
}

\begin{abstract}
${ }^{1}$ Department of Endocrinology, Union Hospital, Tongji Medical College, Huazhong University of Science and Technology, Wuhan, Hubei 430022; ${ }^{2}$ Department of Medicine, Tongji Hospital, Tongji Medical College,

Huazhong University of Science and Technology, Wuhan, Hubei 430030;

${ }^{3}$ Department of Integrated Traditional Chinese and Western Medicine, Union Hospital, Tongji Medical College,

Huazhong University of Science and Technology, Wuhan, Hubei 430022, P.R. China
\end{abstract}

Received November 22, 2014; Accepted August 19, 2015

DOI: $10.3892 / \mathrm{mmr} .2015 .4298$

\begin{abstract}
Previous studies have indicated that 4-hydroxyisoleucine (4-HIL) improves insulin resistance, however, the underlying mechanisms remain to be elucidated. In the present study, the molecular mechanisms underlying how 4-HIL improves insulin resistance in hepatocytes were examined. HepG2 cells were co-cultured with insulin and a high glucose concentration to obtain insulin-resistant (IR) HepG2 cells. Insulin sensitivity was determined by measuring the glucose uptake rate. The IR HepG2 cells were treated with different concentrations of 4-HIL to determine its effect on IR Hep 2 cells. The levels of tumor necrosis factor- $\alpha$ (TNF- $\alpha$ ) were measured by an enzyme-linked immunosorbent assay and protein levels of TNF- $\alpha$ converting enzyme (TACE)/tissue inhibitor of metalloproteinase 3 (TIMP3), insulin receptor substrate (IRS)-1, IRS-2, phosphorylated (p)-IRS-1 (Ser307) and glucose transporter type 4 (GLUT4) were measured by western blot analysis. The results of the

Correspondence to: Professor Furong Lu, Department of Integrated Traditional Chinese and Western Medicine, Union Hospital, Tongji Medical College, Huazhong University of Science and Technology, 1277 Jeifang Avenue, Wuhan, Hubei 430022, P.R. China

E-mail: furonglulove@163.com
\end{abstract}

Abbreviations: TNF- $\alpha$, tumor necrosis factor- $\alpha$; TACE, TNF- $\alpha$ converting enzyme; TIMP, tissue inhibitor of metalloproteinase; IRS, insulin receptor substrate; p-IRS, phosphorylated insulin receptor substrate; Ser, serine; GLUT, glucose transporter; PI3K, phosphoinositide 3-kinase

Key words: 4-hydroxyisoleucine, insulin resistance, tumor necrosis factor,TNF- $\alpha$ converting enzyme/tissue inhibitor of metalloproteinase 3 , insulin receptor substrate 1 , insulin receptor substrate 2, phosphorylation of insulin receptor substrate 1 (Ser307), glucose transporter type 4 present study demonstrated that insulin-induced glucose uptake was reduced in IR HepG2 cells; however, this reduction was reversed by 4-HIL in a dose-dependent manner. 4-HIL achieved this effect by downregulating the expression of TNF- $\alpha$ and TACE, and upregulating the expression of TIMP3 in IR HepG2 cells. In addition, 4-HIL increased the expression of the insulin transduction regulators IRS-1 and GLUT4, and decreased the expression of p-IRS-1 (Ser307), without affecting the expression of IRS-2. The present study suggests that 4-HIL improved insulin resistance in HepG2 cells by the following mechanisms: 4-HIL reduced TNF- $\alpha$ levels by affecting the protein expression of the TACE/TIMP3 system and 4-HIL stimulated the expression of IRS-1 and GLUT4, but inhibited the expression of p-IRS-1 (Ser307).

\section{Introduction}

Insulin resistance is a pathological condition that precedes several disease states, including hypertension, obesity, dyslipidemia and type 2 diabetes $(1,2)$. Insulin resistance is characterized by inadequate regulation of nutrient metabolism and glucose uptake, in numerous tissues and organs, including the liver.

Tumor necrosis factor- $\alpha$ (TNF- $\alpha)$ is synthesized as a membrane-anchored $26-\mathrm{kDa}$ precursor and is cleaved to generate a secretary $17-\mathrm{kDa}$ form by TNF- $\alpha$-converting enzyme (TACE) (3-6). The level of TNF- $\alpha$ is controlled by the TACE/tissue inhibitor of metalloproteinase 3 (TIMP3) system (TIMP3 inhibits TACE activity) (4). TNF- $\alpha$ is important in regulating insulin sensitivity at the intracellular level and in liver and muscle tissue (7). Several studies have demonstrated that TNF- $\alpha$ contributes to the genesis and development of insulin resistance by promoting the phosphorylation of insulin receptor substrate (IRS)-1 at Ser307, inhibiting tyrosine phosphorylation of IRS-1 and downregulating the expression of glucose transporter type 4 (GLUT4) at the cellular membrane $(3,8-13)$. 
Trigonella foenum-graecum is an herb in the leguminoseae family and is commonly termed fenugreek. Fenugreek is one of the oldest medicinal plants that is widely cultivated across Africa, Asia and Europe $(14,15)$. The amino acid 4-hydroxyisoleucine (4-HIL) is extracted from fenugreek seeds and is $80 \%$ free amino acids (16-18). 4-HIL exists predominantly as the isomeric forms $2 \mathrm{~S}, 3 \mathrm{R}, 4 \mathrm{~S}$ and $2 \mathrm{R}, 3 \mathrm{R}, 4 \mathrm{R}$ (15). According to Broca et al, the major isomeric form of 4-HIL (2S, 3R, 4S) induces insulin secretion by directly affecting pancreatic $\mathrm{B}$ cells in rats and humans (18). Certain studies have found that 4-HIL also improved insulin resistance in skeletal muscle, the liver and in fat tissue $(15,19-22)$. However, the molecular mechanisms underlying how 4-HIL improves insulin resistance remain to be elucidated. A previous study indicated that 4-HIL activated phosphoinositide 3-kinase (PI3K) in the insulin-signaling pathway without affecting the level of insulin in blood plasma (19). The present study was conducted to understand and define the molecular mechanisms underlying how 4-HIL improves insulin resistance in HepG2 cells. Specifically, the aim of the present study was to address the effect of 4-HIL on crosstalk between the inflammatory cytokine TNF- $\alpha$ and insulin signaling transduction in hepatocytes.

\section{Materials and methods}

Cell culture and glucose uptake. The established human HepG2 hepatoma cell line was obtained from the American Type Culture Collection (Rockville, MD, USA). The HepG2 cells were grown in Dulbecco's modified Eagle's medium (DMEM; Sigma-Aldrich, Shanghai, China) supplemented with $10 \%$ fetal bovine serum (Gibco, Beijing, China) under standard cell culture conditions (humidified atmosphere, 5\% $\mathrm{CO}_{2}$ and $37^{\circ} \mathrm{C}$ ). The following protocol was used to determine the optimal dose of insulin and treatment duration required to establish insulin-resistant (IR) cells: Initially, 2 days prior to the experiment, the cells were seeded in 24-well plates (with $1.5 \times 10^{4}$ cells/well) with certain wells remaining empty. Secondly, once the cells reached confluence, the medium was replaced with DMEM supplemented with a high glucose concentration (25 mmol/l) and insulin at various concentrations $\left(10^{-9}, 10^{-8}\right.$, $10^{-7}, 10^{-6}$ and $10^{-5} \mathrm{mmol} / \mathrm{l}$ ) for $36 \mathrm{~h}$. Subsequently, the cells were treated with DMEM supplemented with a high glucose concentration $(25 \mathrm{mmol} / \mathrm{l})$ and insulin $\left(10^{-7} \mathrm{mmol} / \mathrm{l}\right)$ for 24,48 and $72 \mathrm{~h}$. At the end of the incubation periods, the medium was removed and glucose concentrations were determined using the glucose oxidase method. HepG2 cell glucose uptake was calculated by subtracting the glucose concentration of the wells with cells from the glucose levels of the blank wells. The established IR HepG2 cells were then treated with different concentrations of 4-HIL $(0,5,10,20$ and $40 \mu \mathrm{mol} / 1)$ for $24 \mathrm{~h}$ and glucose uptake was determined as described above.

Enzyme-linked immunosorbent assay (ELISA). The culture medium was collected and centrifuged at $200 \mathrm{x}$ g for $10 \mathrm{~min}$ to remove undue particles and the supernatant was analyzed for TNF- $\alpha$ levels using a human TNF- $\alpha$ ELISA kit (Neobioscience, Shenzhen, China).

Western blotting. Whole-cell lysates were extracted using radioimmunoprecipitation assay buffer (Abcam, Shanghai,
China) supplemented with phosphatase inhibitors diluted 1:100 and a protease inhibitor cocktail diluted 1:50 (Wuhan Huge Biotechnology Co., Ltd., Wuhan, China). The cell lysates (30 $\mu \mathrm{g}$ of protein) were dissolved in 5X SDS-PAGE protein sample buffer (Beyotime Institute of Biotechnology, Haimen, China) and were boiled for 5-10 min at $100^{\circ} \mathrm{C}$. The samples were then separated by SDS-polyacrylamide gel electrophoresis and electrotransferred onto polyvinylidene difluoride membranes (Millipore, Beijing, China). Biotinylated markers (Fermentas, Vilnius, Lithuania) were used as a molecular weight indicator. The polyvinylidene difluoride membranes were then blocked for $1 \mathrm{~h}$ using $5 \%$ bovine serum albumin in Tris-buffered saline and Tween 20 (TBST). Following being washed three times with TBST, the membranes were incubated overnight with the following primary antibodies: Polyclonal anti-TIMP3 rabbit anti-human antibody (ab39184; 1:1,000; Abcam, Cambridge, UK), polyclonal anti-TACE rabbit anti-human antibody (ab2051; 1:1,000; Abcam), monoclonal anti-IRS-1 rabbit anti-human antibody (\#3407; 1:1,000; Cell Signaling Technology, Inc., Boston, MA, USA), monoclonal anti-IRS-2 rabbit anti-human antibody (\#4502; 1:1,000; Cell Signaling Technology, Inc.), monoclonal anti-Phospho-IRS-1 (Ser307) rabbit anti-human antibody (\#2381; 1:1,000; Cell Signaling Technology, Inc.), polyclonal anti-Glut4 goat anti-human antibody (sc-1608; 1:1,000; Santa Cruz Biotechnology, Inc., Santa Cruz, CA, USA), and monoclonal anti- $\beta$-actin mouse anti-human antibody (sc-47778; 1:1,000; Santa Cruz Biotechnology, Inc.). Subsequently, the membranes were washed three times with TBST and were then incubated with secondary antibodies (1:1,000; goat anti-mouse IgG-HRP, sc-2005; goat anti-rabbit IgG-HRP, sc-2004; Santa Cruz Biotechnology, Inc.) for $1 \mathrm{~h}$. The membranes were then washed three times with TBST and the immunoreactive proteins were detected using ECL plus western blotting detection reagents (Beyotime Institute of Biotechnology, Nantong, China).

Statistical analysis. All experiments were performed in duplicate and were repeated at least two or three times. Each experiment yielded almost identical results and the data are expressed as the mean \pm standard deviation. The differences between groups were determined by a one-way analysis of variance. Statistical analysis was performed using SPSS software v.19 (SPSS Inc., Armonk, NY, USA). P<0.05 was considered to indicate a statistically significant difference.

\section{Results}

Establishing an IR cell line. In order to develop an IR cell line, the HepG2 cells were initially treated with different concentrations of insulin for $36 \mathrm{~h}$ (Fig. 1A). The results indicate that the lowest glucose uptake occurred at an insulin dose of $10^{-7} \mathrm{mmol} / 1$ (Fig. 1A). HepG2 cells were then exposed to $10^{-7} \mathrm{mmol} / 1$ insulin for 24,48 and $72 \mathrm{~h}$ (Fig. 1B) and the results demonstrated that insulin-induced glucose uptake was lowest at $24 \mathrm{~h}$ (Fig. 1B). Therefore, the IR HepG2 cells used in the present study were established using $10^{-7} \mathrm{mmol} / \mathrm{l}$ insulin administered to the cells for $24 \mathrm{~h}$. In order to determine the stability of the model, the IR cells were grown in medium without insulin for 24,48 and $72 \mathrm{~h}$ 
A
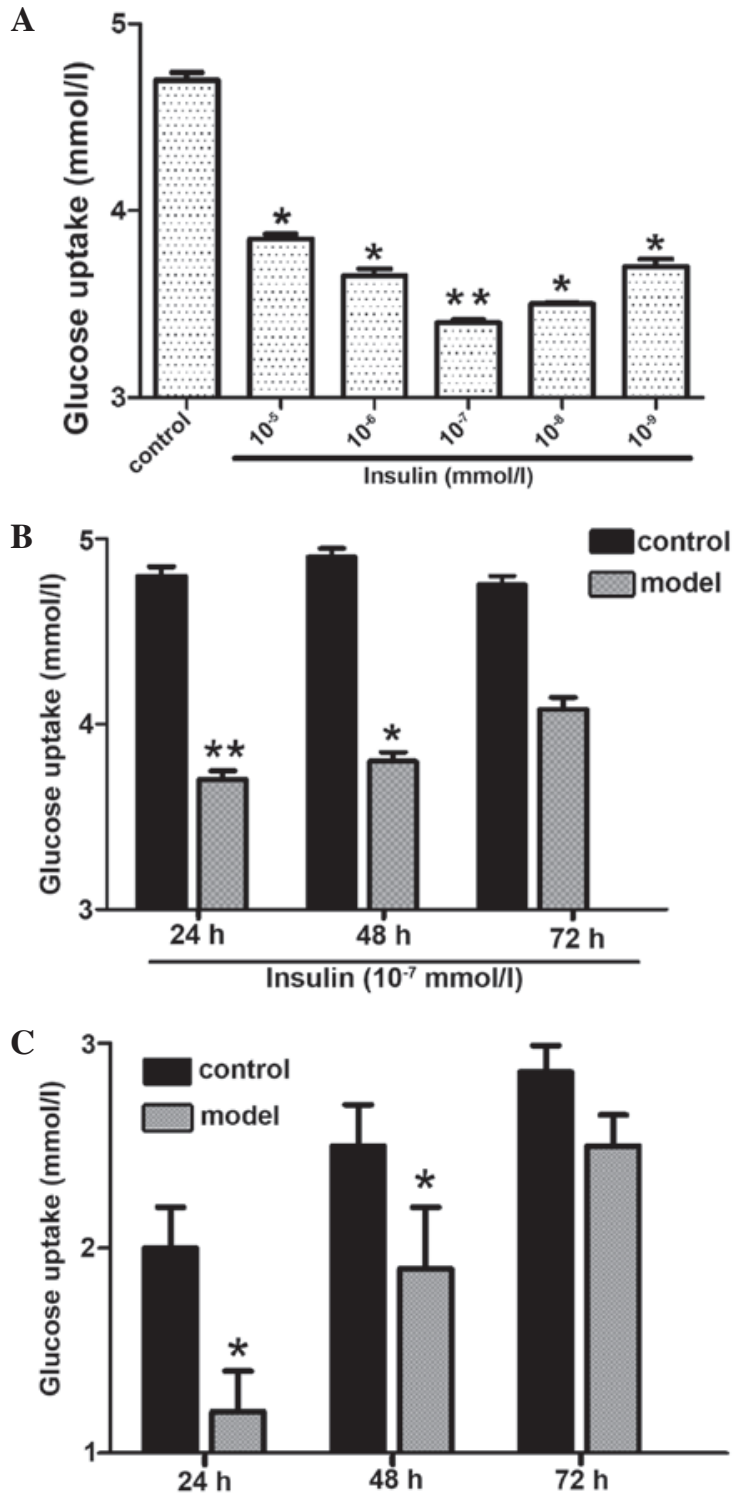

Figure 1. Establishment of an insulin-resistant cell line. (A) Effect of insulin concentration on glucose uptake by HepG2 cells. (B) Effect of insulin treatment time on insulin-induced glucose uptake by HepG2 cells. (C) Glucose uptake stability of insulin-resistant HepG2 cells $\left({ }^{* *} \mathrm{P}<0.01\right.$ and ${ }^{*} \mathrm{P}<0.05$ vs. control).

(Fig. 1C) and the results show that the IR cells remained stable for $48 \mathrm{~h}$.

4-HIL improves insulin resistance in IR HepG2 cells. The IR HepG2 cells were treated with different doses of 4-HIL for $24 \mathrm{~h}$ (Fig. 2) and it was found that insulin-induced glucose uptake was increased in a dose-dependent manner with the maximal effect observed at $20 \mu \mathrm{mol} / 1$ 4-HIL. These data suggest that 4-HIL improves insulin sensitivity in IR HepG2 cells in a dose-dependent manner.

4-HIL inhibits TNF- $\alpha$ in IR HepG2 cells. In order to understand the potential mechanisms underlying how 4-HIL improves insulin resistance, the effect of 4-HIL on TNF- $\alpha$ levels in IR HepG2 cells was investigated. The results in Fig. 3 show that TNF- $\alpha$ levels were markedly increased in IR HepG2 cells $(0 \mu \mathrm{mol} / \mathrm{l})$ compared with the control cells $(\mathrm{P}<0.001)$,

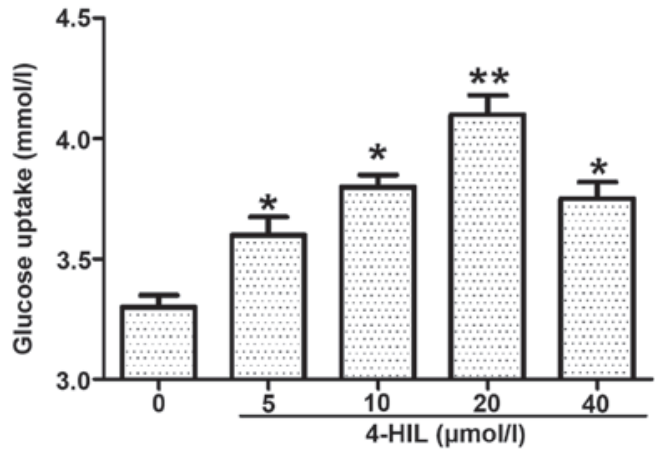

Figure 2. Dose-dependent effect of 4-HIL on the glucose uptake of insulin-resistant HepG2 cells $\left({ }^{* *} \mathrm{P}<0.01\right.$ and ${ }^{*} \mathrm{P}<0.05$ vs. $\left.0 \mu \mathrm{mol} / 1\right)$. $4-\mathrm{HIL}$, 4-hydroxyisoleucine.

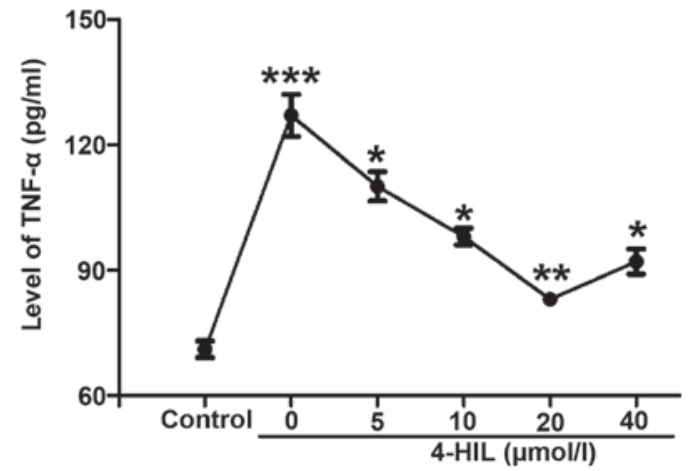

Figure 3. Effect of 4-HIL on TNF- $\alpha$ levels in IR HepG2 cells $\left({ }^{* * *} \mathrm{P}<0.001\right.$ vs. control; ${ }^{* *} \mathrm{P}<0.01$ and ${ }^{*} \mathrm{P}<0.05$ vs. IR cells). TNF- $\alpha$, tumor necrosis factor- $\alpha$; 4-HIL, 4-hydroxyisoleucine; IR, insulin resistant.

but decreased significantly in a dose-dependent manner with increasing concentrations of 4-HIL. These results indicated that 4-HIL dose-dependently inhibited the overproduction of TNF- $\alpha$ in IR HepG2 cells.

4-HIL upregulates the expression of TIMP3 and downregulates the expression of TACE in IR HepG2 cells. Since TNF- $\alpha$ release is controlled by the TACE/TIMP3 system, the role of 4-HIL in regulating the protein expression of TIMP3 and TACE was further investigated in IR HepG2 cells. The results in Fig. 4A show that IR HepG2 cells overexpressed TACE and underexpressed TIMP3 when compared with the control cells. Notably, 4-HIL dose-dependently downregulated and upregulated TACE and TIMP3 expression in IR HepG2 cells, respectively (Fig. 4B). The observed 4-HIL-mediated downregulation of TACE and upregulation of TIMP3 expression in IR HepG2 cells provides evidence that the TACE/TIMP3 system may be the determining factor for overproduction of TNF- $\alpha$ in IR HepG2 cells.

4-HIL regulates the expression of key proteins involved in the insulin-signaling pathway in IR HepG2 cells. Whether 4-HIL directly affected the expression of the insulin signal transduction proteins IRS-1/2 was next examined, including phosphorylation of IRS-1 at Ser307 (p-IRS-1) and GLUT4. The results shown in Fig. 5A demonstrated that IR HepG2 cells expressed lower levels of IRS-1 and GLUT4, higher levels of 
A
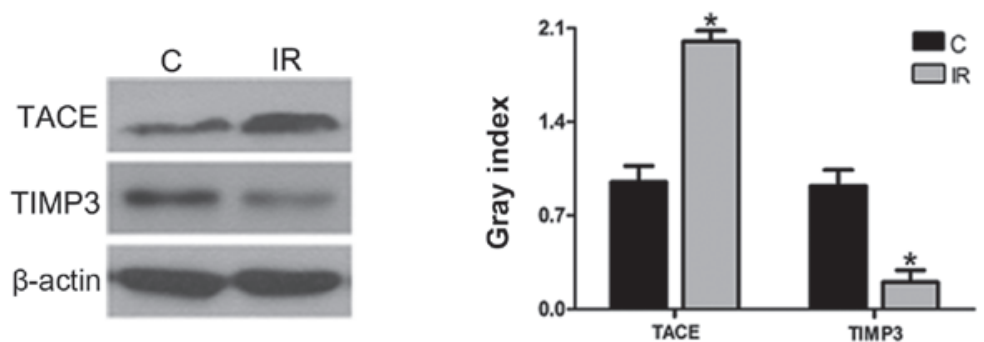

B
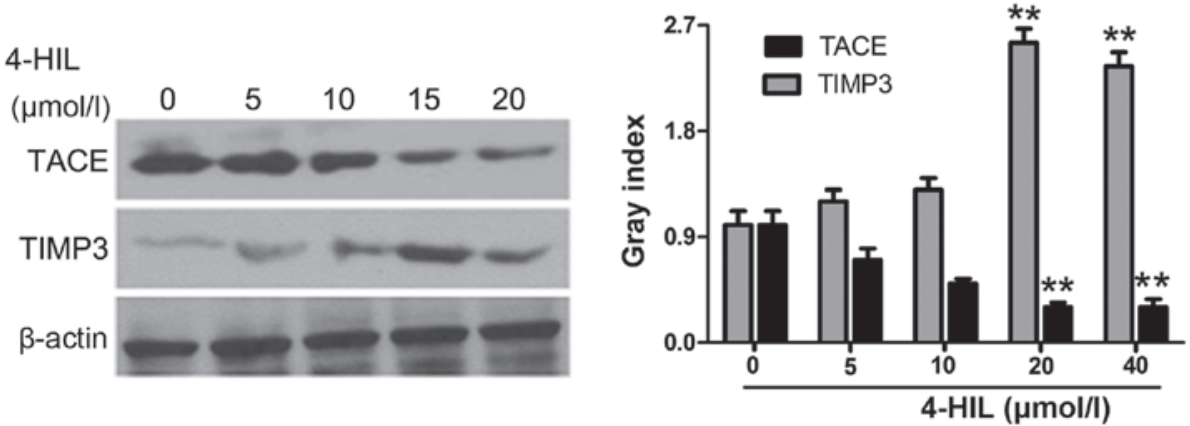

Figure 4. Effects of different concentrations of 4-HIL on the expression of the TACE/TIMP3 system in IR HepG2 cells. The left and right panels of A and B show western blotting and quantitative analysis of each band, respectively. (A) Expression of the TACE/TIMP3 system in control cells and IR HepG2 cells ( $\mathrm{P}<0.05$ vs. control). (B) Expression of the TACE/TIMP3 system in IR HepG2 cells following treatment with different concentrations of 4-HIL $\left({ }^{* *} \mathrm{P}<0.01 \mathrm{vs}\right.$. $0 \mu \mathrm{mol} / \mathrm{l}) .4$-HIL, 4-hydroxyisoleucine; TACE, TNF- $\alpha$ converting enzyme; TIMP3, tissue inhibitor of metalloproteinase 3 ; C, control cells; IR, insulin-resistant cells.

A

B

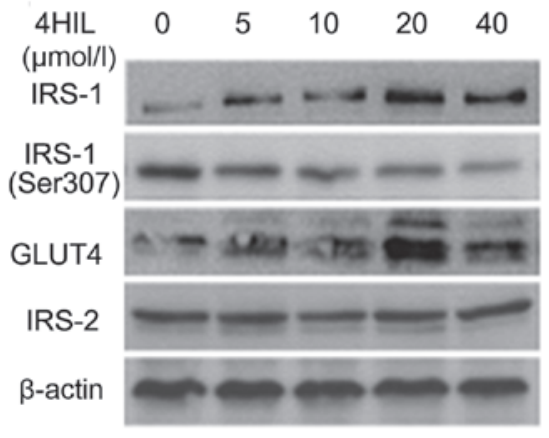

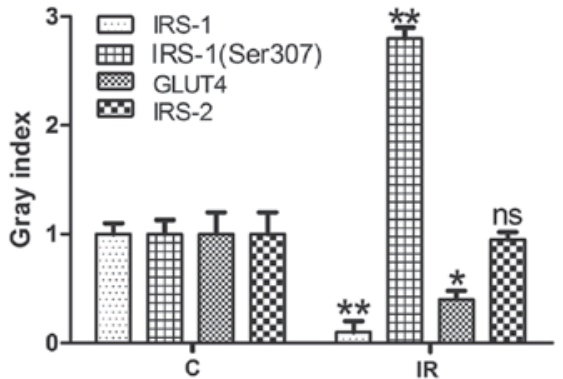

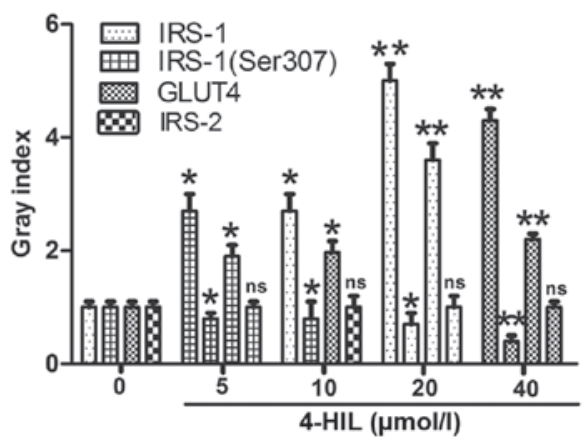

Figure 5. Expression of insulin signal transduction proteins in IR HepG2 cells prior to and following exposure to different concentrations of 4-HIL. The left and right panels of A and B show western blotting and quantitative analysis of each band, respectively. (A) Expression of insulin signal transduction proteins in the control cells and IR HepG2 cells ( $\mathrm{P}<0.05$ and ${ }^{* *} \mathrm{P}<0.01$ vs. control cells). (B) Expression of insulin signal transduction proteins in IR HepG2 cells exposed to different concentrations of 4-HIL ( $\left(\mathrm{P}<0.05\right.$ and ${ }^{* *} \mathrm{P}<0.01$ vs. $\left.0 \mu \mathrm{mol} / \mathrm{l}\right)$. 4-HIL, 4-hydroxyisoleucine; IRS-1/2, insulin receptor substrate 1/2; GLUT, glucose transporter type 4; C, control cells; IR, insulin-resistant cells; ns, not significant.

p-IRS-1 and equivalent levels of IRS-2 when compared with the control cells. The results shown in Fig. 5B demonstrate that 4-HIL dose-dependently upregulated IRS-1 and GLUT4 expression, downregulated the expression of p-IRS-1 and had no effect on IRS-2 expression in IR HepG2 cells. These results indicate that 4-HIL directly affected expression of key insulin signal transduction proteins in addition to regulating TNF- $\alpha$ expression. 


\section{Discussion}

4-HIL is an atypical branched-chain amino acid derived from fenugreek that stimulates glucose-dependent insulin secretion by directly affecting pancreatic islets and reduces insulin resistance in muscle and/or the liver $(15,16,19,23)$. However, the molecular mechanisms underlying how 4-HIL improves insulin resistance remain to be elucidated. Broca et al indicated that a potential mechanism of action mediated by 4-HIL may be through activation of PI3K in the insulin signaling pathway (19). In order to further delineate the molecular mechanisms regulating 4-HIL-mediated improvements in insulin resistance, the effect of 4-HIL on crosstalk between the inflammatory cytokine TNF- $\alpha$ and proteins in the insulin signal transduction pathway was investigated in IR HepG2 cells.

An IR HepG2 cell line was established by initially treating HepG2 cells with $10^{-7} \mathrm{mmol} / \mathrm{l}$ insulin for $24 \mathrm{~h}$. The IR HepG2 cell line demonstrated markedly decreased glucose uptake, thus indicating successful establishment of an IR cell line. The molecular mechanism underlying how 4-HIL improves insulin resistance was then examined following identifying that 4-HIL significantly increased glucose uptake in a dose-dependent manner in IR HepG2 cells.

Insulin binding to its receptor induces activation of downstream molecules, including insulin receptor tyrosine kinase, phosphorylation of IRS-1 on multiple tyrosine residues, PI3K and the serine/threonine kinase PI3K-linked protein kinase B (Akt/PKB) (24,25). The activation of Akt/PKB stimulates GLUT4, which results in enhanced glucose uptake (26). Previous studies have demonstrated that insulin resistance is most likely attributed to a defect in the insulin receptor/IRS-1/PI3K cascade (19). This defect is initiated by Ser/Thr phosphorylation of IRS-1, which inhibits insulin-stimulated tyrosine phosphorylation of IRS-1 and consequently inhibits the insulin signal transduction pathway, ultimately leading to insulin resistance $(19,27)$.

The present study demonstrated that IR HepG2 cells exhibited a high expression of p-IRS-1 (Ser307), a low expression of IRS-1 and GLUT4, and decreased glucose uptake. The present study also demonstrated that 4-HIL dose-dependently downregulated the expression of p-IRS-1 (Ser307), upregulated the expression of IRS-1 and GLUT4, and increased glucose uptake in IR HepG2 cells. These findings suggest for the first time, to the best of our knowledge, that 4-HIL improves insulin sensitivity by directly affecting the insulin signaling pathway.

Insulin resistance is strongly associated with obesity and other pathological stress conditions, including inflammatory diseases, hemorrhage, thermal injury, sepsis and cancer cachexia. These pathological states are characterized by an increased inflammatory response as indicated by high levels of pro-inflammatory cytokines, including TNF- $\alpha$ (28). Several studies have demonstrated that TNF- $\alpha$ has a central role in obesity-induced insulin resistance by promoting serine phosphorylation of IRS-1, which impairs insulin receptor and IRS-1 interactions and compromises insulin signal propagation $(29,30)$.

The present study determined that TNF- $\alpha$ was significantly increased in IR HepG2 cells and assessed whether 4-HIL affected levels of the cytokine. It was found that 4-HIL significantly decreased TNF- $\alpha$ expression in IR HepG 2 cells and a secondary mechanism involved in how 4-HIL improved insulin resistance in IR cells was highlighted. The present study next aimed to determine the mechanism involved in decreased TNF- $\alpha$ in IR HepG 2 cells.

Several studies have indicated that $\mathrm{TNF}-\alpha$ secretion is dependent on the interaction between TACE and its endogenous inhibitor TIMP3 (13,31-34). In the present study, expression of the TACE/TIMP3 system was detected using immunoblotting and it was demonstrated that expression of TACE was higher, whereas TIMP3 expression was lower in IR HepG2 cells compared with the control cells (Fig. 4A). In addition, 4-HIL dose-dependently upregulated TIMP3 and downregulated TACE expression (Fig. 4B), suggesting that 4-HIL may decrease TNF- $\alpha$ expression in IR HEpG2 cells via its effects on the TACE/TIMP3 system.

In conclusion, an IR HepG2 cell line that exhibited downregulated TIMP3, IRS-1 and GLUT4, upregulated TACE, TNF- $\alpha$ and p-IRS-1 (Ser307), and low glucose uptake was successfully established. The present study also identified that 4-HIL dose-dependently improved insulin resistance in IR HepG2 cells by two potential mechanisms. Firstly, 4-HIL affected expression of the TACE/TIMP3 system that has been previously demonstrated to negatively regulate TNF- $\alpha$ production, thus indirectly increasing insulin sensitivity of the IR cell line (32). Secondly, 4-HIL directly affected protein expression of p-IRS-1 (Ser307), IRS-1 and GLUT4 in the insulin signaling pathway in IR HepG2 cells, thus highlighting an additional mechanism. Notably, IRS-2 expression was not altered in IR HepG2 cells or affected by exposure to 4-HIL. The results from the present study provide evidence that 4-HIL may be a novel and useful clinical tool to combat insulin resistance.

\section{Acknowledgements}

This study was supported by the National Natural Science Foundation of China (grant no. 81001670).

\section{References}

1. Cordain L,Eades MR and Eades MD: Hyperinsulinemic diseases of civilization: More than just Syndrome X. Comp Biochem Physiol A Mol Integr Physiol 136: 95-112, 2003.

2. Xie W, Wang W, Su H, Xing D, Pan Y and Du L: Effect of ethanolic extracts of Ananas comosus L. leaves on insulin sensitivity in rats and HepG2. Comp Biochem Physiol C Toxicol Pharmacol 143: 429-435, 2006.

3. Peraldi P, Hotamisligil GS, Buurman WA, White MF and Spiegelman BM: Tumor necrosis factor (TNF)-alpha inhibits insulin signaling through stimulation of the p55 TNF receptor and activation of sphingomyelinase. J Biol Chem 271: 13018-13022, 1996.

4. Moss ML, Jin SL, Milla ME, Bickett DM, Burkhart W, Carter HL, Chen WJ, Clay WC, Didsbury JR, Hassler D, et al: Cloning of a disintegrin metalloproteinase that processes precursor tumour-necrosis factor-alpha. Nature 385: 733-736, 1997.

5. Bu R, Borysenko CW, Li Y, Cao L, Sabokbar A and Blair HC: Expression and function of TNF-family proteins and receptors in human osteoblasts. Bone 33: 760-770, 2003.

6. Moreira AP, Dias-Melicio LA, Peraçoli MT, Calvi SA and Victoriano de Campos Soares AM: Killing of Paracoccidioides brasiliensis yeast cells by IFN-gamma and TNF-alpha activated murine peritoneal macrophages: Evidence of $\mathrm{H}(2) \mathrm{O}(2)$ and $\mathrm{NO}$ effector mechanisms. Mycopathologia 166: 17-23, 2008. 
7. Takahashi E, Okumura A, Unoki-Kubota H, Hirano H, Kasuga $\mathrm{M}$ and Kaburagi Y: Differential proteome analysis of serum proteins associated with the development of type 2 diabetes mellitus in the KK-A(y) mouse model using the iTRAQ technique. J Proteomics 84: 40-51, 2013.

8. Saghizadeh M, Ong JM, Garvey WT, Henry RR and Kern PA: The expression of TNF alpha by human muscle. Relationship to insulin resistance. J Clin Invest 97: 1111-1116, 1996.

9. Katsuki A, Sumida Y, Murashima S, Murata K, Takarada Y, Ito K, Fujii M, Tsuchihashi K, Goto H, Nakatani K and Yano Y: Serum levels of tumor necrosis factor-alpha are increased in obese patients with noninsulin-dependent diabetes mellitus. J Clin Endocrinol Metab 83: 859-862, 1998.

10. Rui L, Aguirre V, Kim JK, Shulman GI, Lee A, Corbould A, Dunaif A and White MF: Insulin/IGF-1 and TNF-alpha stimulate phosphorylation of IRS-1 at inhibitory Ser307 via distinct pathways. J Clin Invest 107: 181-189, 2001.

11. del Aguila LF, Claffey KP and Kirwan JP: TNF-alpha impairs insulin signaling and insulin stimulation of glucose uptake in C2C12 muscle cells. Am J Physiol 276: E849-E855, 1999.

12. Krogh-Madsen R, Plomgaard P, Møller K, Mittendorfer B and Pedersen BK: Influence of TNF-alpha and IL-6 infusions on insulin sensitivity and expression of IL-18 in humans. Am J Physiol Endocrinol Metab 291: E108-E114, 2006

13. Tang ZY, Loss G, Carmody I and Cohen AJ: TIMP-3 ameliorates hepatic ischemia/reperfusion injury through inhibition of tumor necrosis factor-alpha-converting enzyme activity in rats. Transplantation 82: 1518-1523, 2006.

14. Narender T, Puri A, Shweta, Khaliq T, Saxena R, Bhatia G and Chandra R: 4-hydroxyisoleucine an unusual amino acid as antidyslipidemic and antihyperglycemic agent. Bioorg Med Chem Lett 16: 293-296, 2006.

15. Jetté L, Harvey L, Eugeni K and Levens N: 4-Hydroxyisoleucine: A plant-derived treatment for metabolic syndrome. Curr Opin Investig Drugs 10: 353-358, 2009.

16. Sauvaire Y, Petit P, Broca C, Manteghetti M, Baissac Y, Fernandez-Alvarez J, Gross R, Roye M, Leconte A, Gomis R and Ribes G: 4-Hydroxyisoleucine: A novel amino acid potentiator of insulin secretion. Diabetes 47: 206-210, 1998.

17. Haefelé C, Bonfils C and Sauvaire Y: Characterization of a dioxygenase from Trigonella foenum-graecum involved in 4-hydroxyisoleucine biosynthesis. Phytochemistry 44: 563-566, 1997.

18. Broca C, Manteghetti M, Gross R, Baissac Y, Jacob M, Petit P Sauvaire $\mathrm{Y}$ and Ribes G: 4-Hydroxyisoleucine: Effects of synthetic and natural analogues on insulin secretion. Eur J Pharmacol 390: 339-345, 2000.

19. Broca C, Breil V, Cruciani-Guglielmacci C, Manteghetti M, Rouault C, Derouet M, Rizkalla S, Pau B, Petit P, Ribes G, et al: Insulinotropic agent ID-1101 (4-hydroxyisoleucine) activates insulin signaling in rat. Am J Physiol Endocrinol Metab 287: E463-E471, 2004.

20. Savage DB, Petersen KF and Shulman GI: Mechanisms of insulin resistance in humans and possible links with inflammation. Hypertension 45: 828-833, 2005.

21. Haeri MR, Izaddoost M, Ardekani MR, Nobar MR and White KN: The effect of fenugreek 4-hydroxyisoleucine on liver function biomarkers and glucose in diabetic and fructose-fed rats. Phytother Res 23: 61-64, 2009.
22. Henkel J, Neuschäfer-Rube F, Pathe-Neuschäfer-Rube A and Püschel GP: Aggravation by prostaglandin E2 of interleukin-6-dependent insulin resistance in hepatocytes. Hepatology 50: 781-790, 2009.

23. Ogawa J, Kodera T, Smirnov SV, Hibi M, Samsonova NN Koyama R, Yamanaka H, Mano J, Kawashima T, Yokozeki K and Shimizu S: A novel L-isoleucine metabolism in Bacillus thuringiensis generating $(2 \mathrm{~S}, 3 \mathrm{R}, 4 \mathrm{~S})$-4-hydroxyisoleucine, a potential insulinotropic and anti-obesity amino acid. Appl Microbiol Biotechnol 89: 1929-1938, 2011.

24. Zhang WY, Lee JJ, Kim IS, Kim Y, Park JS and Myung CS: 7-O-methylaromadendrin stimulates glucose uptake and improves insulin resistance in vitro. Biol Pharm Bull 33 1494-1499, 2010

25. Khan AH and Pessi JE: Insulin regulation of glucose uptake: A complex interplay of intracellular signalling pathways. Diabetologia 45: 1475-1483, 2002.

26. Wang Q, Somwar R, Bilan PJ, Liu Z, Jin J, Woodgett JR and Klip A: Protein kinase B/Akt participates in GLUT4 translocation by insulin in L6 myoblasts. Mol Cell Biol 19: 4008-4018, 1999.

27. Miura A, Ishizuka T, Kanoh Y, Ishizawa M, Itaya S, Kimura M, Kajita K and Yasuda K: Effect of tumor necrosis factor-alpha on insulin signal transduction in rat adipocytes: Relation to PKCbeta and zeta translocation. Biochim Biophys Acta 1449: 227-238, 1999.

28. Tal R, Pavlovsky L and David M: Psoriasis and cardiovascular risk factors. Harefuah 151: 573-575, 2012 (In Hebrew).

29. Xin-Long C, Zhao-Fan X, Dao-Feng B and Wei D: mTOR partly mediates insulin resistance by phosphorylation of insulin receptor substrate-1 on serine (307) residues after burn. Burns 37: 86-93, 2011

30. Hotamisligil GS, Peraldi P, Budavari A, Ellis R, White MF and Spiegelman BM: IRS-1-mediated inhibition of insulin receptor tyrosine kinase activity in TNF-alpha- and obesity-induced insulin resistance. Science 271: 665-668, 1996.

31. Monroy A, Kamath S, Chavez AO, Centonze VE, Veerasamy M, Barrentine A, Wewer JJ, Coletta DK, Jenkinson C, Jhingan RM, et al: Impaired regulation of the TNF-alpha converting enzyme/tissue inhibitor of metalloproteinase 3 proteolytic system in skeletal muscle of obese type 2 diabetic patients: A new mechanism of insulin resistance in humans. Diabetologia 52: 2169-2181, 2009.

32. Federici M, Hribal ML, Menghini R, Kanno H, Marchetti V, Porzio O, Sunnarborg SW, Rizza S, Serino M, Cunsolo V, et al: Timp3 deficiency in insulin receptor-haploinsufficient mice promotes diabetes and vascular inflammation via increased TNF-alpha. J Clin Invest 115: 3494-3505, 2005.

33. Serino M, Menghini R, Fiorentino L, Amoruso R, Mauriello A, Lauro D, Sbraccia P, Hribal ML, Lauro R and Federici M: Mice heterozygous for tumor necrosis factor-alpha converting enzyme are protected from obesity-induced insulin resistance and diabetes. Diabetes 56: 2541-2546, 2007.

34. Smookler DS, Mohammed FF, Kassiri Z, Duncan GS, Mak TW and Khokha R: Tissue inhibitor of metalloproteinase 3 regulates TNF-dependent systemic inflammation. J Immunol 176: 721-725, 2006. 